\title{
IoT-based smart learning environment for telecoms students
}

\author{
O. I. Nazarenko, O. O. Rybak
}

\author{
National Technical University of Ukraine \\ "Igor Sikorsky Kyiv Polytechnic Institute", Kyiv, Ukraine \\ Corresponding author. E-mail: nazarenkoits@gmail.com
}

Paper received 03.04.19; Accepted for publication 20.04.19.

\section{https://doi.org/10.31174/SEND-PP2019-198VII80-06}

\begin{abstract}
The article is devoted to the innovative approach to setting up smart learning environment based on the IoT technology. The described preliminary study of the possibilities to create the IoT platform for implementing smart learning included the theoretical and empirical methods. The analysis of works on properties and perspectives of the IoT technology enabled generalizing its benefits for creating smart environment to teach specific disciplines as well as English for Specific Purposes to telecoms students. The authors presented the concept of implementing smart environment - IoT solution for smart learning in the Institute of Telecommunication Systems of the National Technical University of Ukraine "Igor Sikorsky Kyiv Polytechnic Institute".
\end{abstract}

Keywords: IoT, ESP, smart environment, smart learning, LoRaWAN.

Introduction. Telecoms are considered to be one of the most evolutionary and highly dynamic industry in the world. None of the existing businesses or manufactures today can perform without using information and communication technology (ICT). Globalization has caused streamline processes in each sphere of our life; it has brought world markets to global competition, multivendor integration, mass customization, synchronization of manufacturing operations and integration of global supply management.

Smart technologies like the Internet of things (IoT) are changing radically the way we live, study and work. The clouds enable storing enormous chunks of information, big data allows business people to understand how to perform different operations and collaborate with customers; software and robotic machines make manufacturers to produce sophisticated products. All these trends are influencing our self-esteem and attitudes to our lifestyle, work conditions, education and professional training.

Teachers, educators and coaches are trying to find the efficient solutions to how to eliminate the gap between the fast-growing needs in high-performing employees [11] and abilities of those who have to meet these needs the gap between the employment market demands and opportunities of the education system.

Guided by these considerations we have to find all possible ways to create the most effective environment and conditions for teaching and professional training to meet our students' needs to be competitive candidates for different market positions.

Theoretical Background. As predicted [9, p.p. 120], the key trends that impact the future of our work today are: globalization, mobility, millennials in the workplace, new behaviors and technologies.

Globalization is regarded as a tool for prosperity and growing interdependence of world's economies, cultures, technologies and populations. While encouraging competitiveness it promotes economic growth, makes production more efficient, lowers prices of goods and services, provides better quality and variety. It boosts the spread of technology, innovation and communication, and thus, changes types of jobs opening up new and better-paying job opportunities [5].

Moreover, globalization impacts the way we teach our students any specific disciplines or English for Specific Purposes (ESP), since English is becoming to be a com- mon world language and globalization spurs the availability of cheap, rapid and reliable communications [18].

Mobility is ensured by ICT and the access to the world wide web, providing opportunities to work "on the move" and allowing teleworking or telecommuting that means to do business and perform work duties remotely.

Millennials in the workplace, as stated in the research [9, p.p. 1-20], are another obvious trend to shape the future work. Millennials are considered to be individuals born from 1982 to roughly 2005 belong to Generation Y and the newest the Homeland Generation, born roughly 2005-2025 [4, p. 45]. They are also called the Net Generation as it is the first generation to have grown up with computer and the Internet technologies and live in an "electronics-filled and increasingly online and sociallynetworked world" [14]. They easily adjust to new gadgets and software, willingly use new programs, operating systems, quickly perform computer-based tasks, are familiar with programming and hardware issues.

As employees they are expected to make up about $50 \%$ of the world's workforce by 2020 and about $75 \%$ by 2025 [10], and might bring new work styles, innovative approaches and unusual ideas.

According to the presented analysis the new shapes of peoples' behavior result from great influence by social technologies such as LinkedIn, Facebook, Google, Yelp, etc. People become dependent on the Internet for doing their jobs, studying at school or university, learning how to do things or just communicating with each other.

The biggest impact on our life is expected due to the cloud and collaboration platforms, the Internet of Things (IoT) and big data. Since cloud-based technologies help to eliminate the need for any physical installation they might be deployed in any place with the access to the Internet to allow doing businesses, transacting with customers or collaborating with friends, studying new subjects, learning foreign languages or experiencing how to do new things. Collaboration platforms enable connecting people and information together anywhere, anytime, and on any device [9].

In this context learning based on IoT technology is becoming an integral part of the global smart environment and serves as a bridge to eliminate the gap between business/industry and education/professional training.

With regard to the aforementioned, the purpose of the paper is to analyze the possibilities of creating smart 
environment for teaching students in the Institute of Telecommunication Systems (ITS) of the National Technical University of Ukraine "Igor Sikorsky Kyiv Polytechnic Institute" based on the IoT technology as the platform for smart learning.

Methods. Since it was a preliminary study of conditions for piloting the IoT platform for creating relevant environment to implement smart learning in ITS, the research was based on: 1) the theoretical method which included analysis of works on properties and impact on global infrastructure of the IoT technologies and generalization of their benefits for creating smart environment for teaching specific disciplines and ESP to telecoms students; 2) the empirical method which involved interviewing the ITS master students (both scientific and professional) about the level of their awareness of using IoT technologies in education and readiness to be engaged into smart environment for academic purposes.

Review of the Related Literature. As we have mentioned it was a preliminary study aimed at analyzing different specifications of the IoT technology and its properties to create smart environments. A great number of books, scientific works and guidelines dedicated to creation of smart environment based on the Internet of Things are presented currently in the world. Our special attention was given to the works of the world's leading experts in IoT field such as: S. Greengard (2015), B. Sinclair (2017), P. Waher (2018), J. Rossman (2016), T. Chou (2016), C. Martin (2018), C. Pfister (2011), D. Uckelmann, M. Harrison, F. Michahelles (2011) and the Ukrainian specialists: O. Baranov (2016), S. Mohyl'nyy (2016), A. Nakonechnyy \& Z. Veres (2016).

The authors provide an in-depth look into IoT presenting its history and evolution, explaining how it works and how to design and deploy a powerful IoT strategy, analyzing the values and flaws of the technology, predicting its impact on our future life and workstyles, giving expert guidance for those who intent to implement IoT in business environment. They focus on developing applications and services, offer efficient methods and approaches to utilize sensors, cloud computing and machine learning.

To understand properly the concept of IoT technology it was necessary to define it clearly and concisely. The biggest problem seemed to be with a clear definition of IoT. Some researchers stated that it was not well defined $[1,16,17]$, whereas the team of the authors [16] suggested the definition formulated in the Strategic Research Agenda of the Cluster of European Research Projects on the Internet of Things (CERP-IoT 2009): "Internet of Things (IoT) is an integrated part of Future Internet defined as a dynamic global network infrastructure with self-configuring capabilities based on standard and interoperable communication protocols where physical and virtual 'things' have identities, physical attributes, and virtual personalities and use intelligent interfaces, and are seamlessly integrated into the information network." [16, p. 4]. The Internet of Things is presented as "a concept in which the virtual world of information technology integrates seamlessly with the real world of things. The real world becomes more accessible through computers and networked devices in business as well as everyday scenarios" [16, p.2].

The term "Internet of Things" was formulated also in the context of legal science due to the unambiguous understanding of the functional purpose of the Internet of Things "as a means of implementing public relations, which determines the peculiarities of the legal regulation of these relations" $[1,103]$.

P. Waher focuses on the importance of clear understanding of the subject and offers dividing IoT into four areas of study: 1) how to connect things (the study of communication protocols); 2) the study of things (sensors, actuators, controllers, etc.); 3 ) the study of decision, support, artificial intelligence, etc.; 4) the study of security $[17$, p.p. 1-2).

In the work [13, p.p. 1-4) IoT is designed as the IoT Technology Chain with key technologies of most IoT solutions including devices and sensors, connectivity, cloud processing and storage, analytics and machine learning, and described as a structure made up of a growing body of sensors around the world collecting and transmitting data and being able to create digital awareness of the physical world.

The research [6, p.p. 1-4). presents IoT as the $3^{\text {rd }}$ digital transformation (the $1^{\text {st }}$ was the Internet, the $2^{\text {nd }}-$ mobile) comparing it with a technological tsunami which is about to shake every business to its core and structures 7 major elements of the IoT: sensors, artificial intelligence, voice assistants, smart homes, virtual and augmented reality, connected cars, drones and robots.

In another research [3] it is asserted that IoT is just getting started, but in the nearest future it "will serve as the practical framework for life and business", offering "both a telescope and microscope into the once invisible world between people, machines and physical objects", recognizing relationships and predicting patterns which people are unable to see or understand.

The framework that covers the major components of IoT application was designed [2], which is a five-layer, vendor-neutral framework that can be used by technical as well as business specialists.

Still another research $[15$, p.3] proves that IoT enables greatly increasing value and competitiveness of any product or company and predicts that this technology will rewire every industry in its path becoming an integral part of every business, commercial, industrial or consumer environment.

Most researchers advocate the importance of being aware of IoT technologies because despite the fact that people feel more comfortable exchanging information or communicating via different types of social and collaboration platforms they might be uncertain at their workplaces where they have to employ technologies different from those they use in their personal lives. In this regard IoT has a great impact on all spheres of our life and this impact is inevitable on education and professional training as well.

That brought us to interview ITS scientific and professional master students about the level of their awareness of using IoT technologies in education and analyze whether they are interested to be engaged into smart environment for academic purposes.

Findings. We have found out that 100\% (58 students) of our students are familiar with IoT technology since this direction is integrated into specific disciplines they study in the frame of the curriculum. They understand the main 
principles of this technology, its system architecture, a wide range of applications (consumer, commercial, industrial, infrastructural). Those students who work in businesses are able to evaluate the benefits of using IoT for commercial purposes. All the students in ITS utilize smart phones and laptops in their study using different applications, as well as for social activity creating communities based on available web platforms. At the same time very few students (12) know about learning practices based on the Internet of Things in education but they understand that learning is powered by technology, and are interested in experiencing to immerse into smart environment. Our students are able to assess the IoT possibilities to enhance their learning capabilities and make it easy, diverse, interesting, comfortable and more differentiated, individualized and personalized. Most of the master students start gaining professional experience in Telecoms while studying in the institute, so they would prefer to learn at any time, from any place.

Furthermore, the proposed concept for step-by-step introduction of the IoT technology for studying it within the framework of the discipline "Telecommunications and Radio Engineering" [8] would allow teaching students to design an entire system using the Internet of Things.

In terms of ESP learning the students are sure that IoT technology will bring a wide range of opportunities to master language skills and enhance vocabulary providing multiple and flexible means of engagement into Englishrelated environment and powerful tools for reducing language barriers and thus, make them feel more motivated.

Regarding different possibilities and benefits of using IoT technology we would like to present the analysis of IoT integration into teaching/learning processes.

Analysis of IoT Solution. The higher education system of Ukraine is being modernized due to the integration processes, new teaching models, techniques and approaches are being introduced. But it is impossible to understand in a short time how effective change is and what benefits students get. Lecturers must constantly update their methods and ways of knowledge transfer integrating more effective technologies into classes.

As we have mentioned above the Internet of Things has changed the way people and objects interact with each other. Education has undergone significant changes thanks to the Internet of Things. This technology creates new forms of teaching/learning and interaction between lecturers and students in universities, that helps to improve the quality of education, access to educational materials, academic performance and fair assessment.

The Internet of Things is an integral part of the multimedia class to create an ecosystem into which students and lecturers are immersed. Students are able to get full understanding of a topic of any subject they study. Such environment also allows students to communicate in the created group as well as with other students and educators through available online resources (webinars, online communities, etc.). Each student is assisted on the basis of the collected data beyond the university space.

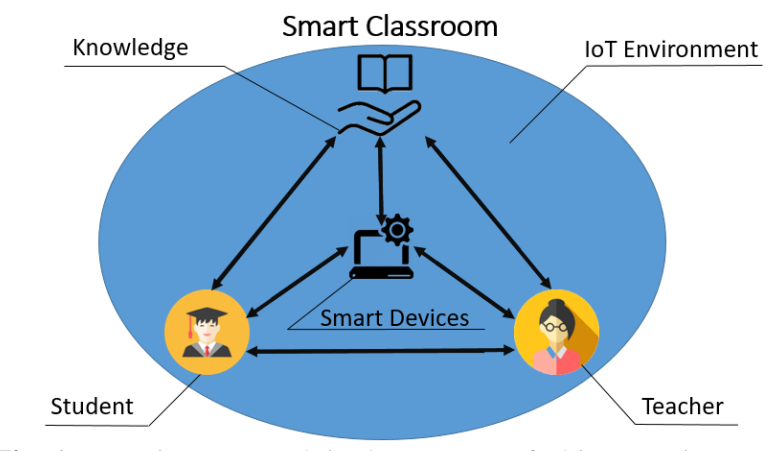

Fig. 1. Learning approach in the Internet of Things environment

Fig.1 demonstrates the learning approach in the Internet of Things environment in which the teacher, students and knowledge are interacted: data are exchanged between the teacher and students demonstrating their status, allowing them to control remotely actions of things, analyze data by means of machine learning, big data, artificial intelligence, virtual reality in order to optimize the process of study. In the learning environment created by the Internet of Things smart devices are able to read information, analyze it and provide each student with an individual approach to learn the material.

The idea of creating a smart environment for learning based on IoT technology has been generated in the Institute of Telecommunication Systems of the National Technical University of Ukraine "Igor Sikorsky Kyiv Polytechnic Institute". The main goal is to create an innovative multimedia class which will help telecoms students to acquire specialism-related knowledge as well as master ESP skills, improve acquisition of complex materials, allow students to study more effectively, feel more interested and motivated and enable educators to modernize existing teaching methods. Smart environment is going to be created on the basis of the Internet of Things Laboratory in which the LoRaWAN technology will be studied and the relevant testing will be conducted.

LoRaWAN is a low-power network protocol (LPWA) designed for the Internet of Things, which can connect various LoRa things on batteries to regional, national or global networks [7]. LoRaWAN operates in the licensefree spectrum [12] that makes it possible to deploy a private network without any problems. The coverage of the LoRaWAN network allows creating in hard-to-reach places and working frequency of the technology of 868 $\mathrm{MHz}$. To create smart learning environment a pico gateway is going to be installed in the classrooms, that will create a private LoRaWaN network. For testing, The Things Network (free network server) is to be used in the future to create our own network server and an Application Server.

We believe that the presented solution will allow students to experience different learning styles, participate in the interactive mode of study and share knowledge with others. Learning will become personal, team, dynamic, shared and relevant, and learning continues outside the university as the student will have an access to an unlimited resource of knowledge through the Internet. The system will identify each student on a special card «student's record-book v.2.0» where the student's progress, favorite disciplines, hobbies and other information which characterizes the student will be displayed.

In our future articles it will be created a model to show 
how the data are collected and analyzed from sensors and interactions between students and lecturers in the smart learning environment, and how the Blockchain technology is used to ensure data security.

Conclusion. It is noteworthy that as far as the Internet of Things technology has an enormous impact on all the spheres of our life its integration into educational environment is an inevitable process. It brings unlimited opportunities to professionals in many fields. The IoT platform creates a lot of possibilities to enhance students' learning capabilities providing interesting, comfortable study and ensuring differentiated, individualized and personalized approach to teaching students.

Professional training with the Internet of things, modern multimedia equipment, and the use of modern trends will allow us to help to figure out which specific area is more suitable for the student, therefore, create an individual teaching or training program enabling students to combine study in the university and work in business or industry.

Using this technology for creating smart environment will enable learners to be fully involved into studying specialism-related disciplines increasing their professional knowledge and skills. Smart environment will motivate students to be engaged into ESP learning, immersing them into the language environment and reducing language barriers.

Integrating the Internet of Things into university classes will give the opportunity for the student to reinvest acquired knowledge and experienced strategies outside the class. The student will feel valuable and more motivated.

After completing the preliminary study, it becomes obvious that the research has to be transferred into the next stage related to smart learning methods based on IoT technology.

\section{REFERENCES}

1. Baranov, O. (2016). "Internet rechej” yak pravovy’j termin. ["Internet of things" as a legal term]. Yury`dy`chna Ukrayina, 5-6, 96-103.

2. Chou, T. (2016). Precision: Principles, Practices and Solutions for the Internet of Things. Cloudbook, Inc.

3. Greengard, S. (2015). The Internet of Things. Massachusetts Institute of Technology.

4. Howe, N. \& Strauss, W. (2007). The Next 20 Years: How Customer and Workforce Attitudes Will Evolve. Harvard Business Review. 85(7-8), p.p. 41-52. Retrieved 25 January, 2018 from: https://hbr.org/2007/07/the-next-20-years-howcustomer-and-workforce-attitudes-will-evolve.

5. Kolb, M. (2018). What is Globalization? Peterson Institute for International Economics. Retrieved 25 January 2018 from: https://piie.com/microsites/globalization/what-isglobalization.html

6. Martin, C. (2018). Digital Transformation 3.0: The New Business-to-Consumer Connections of The Internet of Things. NFI Research. USA.

7. Migrating an Internet of Things (IoT) Sensor Design to LoRaWAN. (2018). LoRa Alliance. Semtech Corporation, Camarillo, CA.

8. Mogy`lny`j, S. (2016). Pokrokova pobudova sy`stemy` dlya Internetu rechej [Professional training for Internet of Things technology]. Visny`k Nacional'nogo texnichnogo universy`tetu Ukrayiny` «KPI». Seriya - Radiotexnika. Radioaparatobuduvannya, 65, 73-78.

9. Morgan, J. (2014). The Future of Work: Attract New Talent, Build Better Leaders, and Create a Competitive Organization. Hoboken, New Jersey: John Wiley\&Sons, Inc.

10. Morgan, J. (2017). The 5 Trends Shaping The Future Of Work. Retrieved 3 January, 2018, from: https://www.ie.edu/corporate-relations/insights/the-fivetrends-shaping-the-future-of-work/

11. Nazarenko, O. (2016). Project as an Effective ProfessionallyOriented Technology in ESP Teaching. Visny`k Nacional ’nogo texnichnogo universy`tetu Ukrayiny` «Ky`yivs`ky`j politexnichny`j insty`tut». Seriya: Filologiya. Pedagogika, 7, 31-36.

12. Ram, P., (2018). LPWAN, LoRa, LoRaWAN and the Internet of Things:PART I - Understanding the LPWAN, LoRa and LoRaWAN technology https://medium.com/coinmonks/lpwan-lora-lorawan-and-theinternet-of-things-aed7d5975d5d.

13. Rossman, J. (2016). The Amazon Way on IoT: 10 Principles for Every Leader from the World's Leading Internet of Things Strategies. Clyde Hill Publishing.

14. Rouse, M. \& Haughn M. (2018). Millennials (Generation Y) TechTarget. Whatis.com? Retrieved 25 January, 2018 from: https://whatis.techtarget.com/definition/millennialsmillennial-generation.

15. Sinclair, B. (2017). IoT Inc: How Your Company Can Use the Internet of Things to Win in the Outcome Economy. USA. (Mc Graw-Hill Education).

16. Uckelmann, D., Harrison, M. \& Michahelles, F. (2011). An Architectural Approach Towards the Future Internet of Things. Architecting the Internet of Things (p.p. 1-24), DOI 10.1007/978-3-642-19157-2_1. Springer-Verlag Berlin Heidelberg.

17. Waher, P. (2018). Mastering Internet of Things: Design and create your own IoT applications using Raspberry Pi 3. Birmingham, UK].

18. Williamson, J. (1998). Globalization: The Concept, Causes, and Consequences. Peterson Institute for International Economics (PIIE) December 15, 1998. Retrieved 25 January 2018 from: https://piie.com/commentary/speechespapers/globalization-concept-causes -and-consequences. 